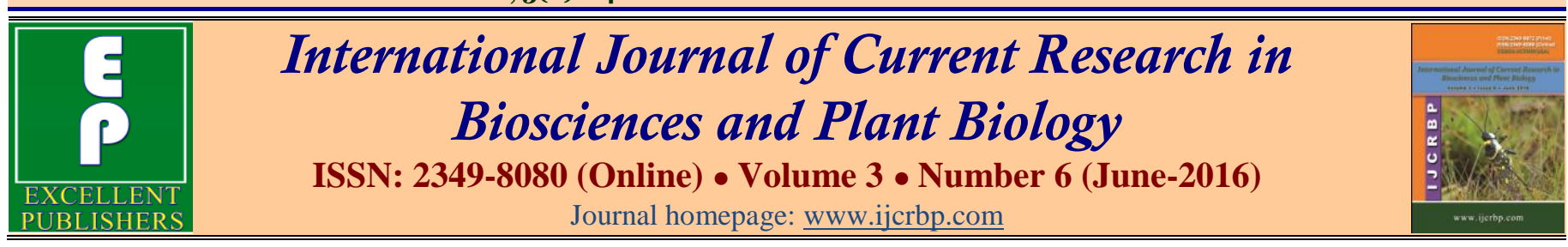

\title{
In Vitro Cytotoxicity and Antibacterial Evaluation of Aqueous, Methanolic and Ethanolic Extracts of Anastatica hierochuntica against Pathogenic Bacteria
}

\author{
Sanad M. Al Sobeai* \\ Sajir College of Arts and Science, Shaqra University, Shaqra, Kingdom of Saudi Arabia \\ *Corresponding author.
}

\begin{abstract}
A b stract
The cytotoxic effect of Anastatica hierochuntica was evaluated in vitro using Vero cell lines, characterized by identification of cellular alterations microscopically and cellular viability colorimetrically. The mean $\mathrm{CC}_{50}$ value of methanol, ethanol, and aqueous extract were lower than $1000 \mu \mathrm{g} / \mathrm{ml}$. The antibacterial activity of ethanol, methanol and aqueous extracts of $A$. hierochuntica was evaluated using agar well diffusion method against 10 bacterial pathogens. All the extracts showed substantial antibacterial activity against the selected pathogens. The methanolic extract showed highest inhibition zone followed by the aqueous and ethanolic extract. Among the bacterial pathogens, $L$. monocytogenes was more resistant towards and ethanol extract. Although, other tested bacteria were susceptible towards aqueous ethanol and methanol extract. However, methanol extract was effective against the tested pathogens, when compared with the other extracts. The minimum inhibitory concentrations (MIC) ranged from $15-50 \mathrm{mg} / \mathrm{ml}$ to inhibit the growth of the tested bacteria. The results show that the plant contains bioactive components which can inhibit the bacterial pathogens which can be further purified and used against the multi-drug resistant bacteria.
\end{abstract}

\section{Introduction}

The use of medicinal plants in the community increased in the recent years for curing some health-related diseases (Sharif and Banik, 2006, Kubmarawa et al., 2007). In some communities consuming herbal drugs and traditional medicine are somewhat more popular because of cultural acceptability and belief that being natural. Medicinal plant has been identified by the WHO as any plant which contains active compounds that can be used for therapeutic tools or which are pioneers for the synthesis of effective safe drugs (Junaid et al., 2006). The various innumerable drugs and pharmaceuticals constitute approximately $40 \%$ plant source (Sharif and Banik, 2006). Infectious diseases are common major global challenge for medical, scientific communities, health organizations and pharmaceutical companies around the world. It has been estimated that 50,000 deaths every day especially with the current increasing trends of multidrug resistance among emerging and reemerging bacterial pathogens to the many available antibiotics (Franklin and Snow, 1989; Prescott et al., 2002). It is therefore very necessary that the search for newer medicinal based antibiotic sources to be a continued process. The plants considered as the cheapest and safer sources for discovering new effective antimicrobials (Pretorious and Watt 2001; Sharif and Banik, 2006; Doughari et al., 2007).

Anastatica hierochuntica $\mathrm{L}$. is a small, winter herb with a 
gray color that grows to an approximately of $10-18 \mathrm{~cm}$ height, with small white flowers. It is found in the some countries such as Saudi Arabia and North Africa. The plant resist and can survive in dry environments without water and then rebirth when water is available and is a well-known desert zone medicinal plant. $A$. hierochuntica is a monocarpic annual plant species characterized by topochory / ombrohydrochory type of seed dispersal (Bellakhdar et al., 1991, Hegazy et al., 2006) (Fig. 1). A. hierochuntica L. (Family: Brassicaceae) is known as Kaff-e Maryam in Saudi Arabia and other Arab countries, where it is widely consumed as a tea beverage and to treatment of many conditions, such as difficult childbirth, blood pressure, diabetes mellitus and uterine hemorrhage (Khalifa and Ahmad, 1980; El-Ghazali et al., 2010; Jaradat, 2005; Sehab et al., 1983; Bellakhdar et al., 1991; Batanouny 1999; Eman et al., 2011; Daur 2012).

In view of its frequent medicinal use and popularity among the people of several countries particularly in Saudi Arabia, Kaff-e-Maryam was selected for the present study. The aim of the present study is to investigate the in vitro cytotoxicity and antibacterial activity of water, ethanol and methanol extracts against ten pathogenic bacteria that cause common and sometimes serious infections in human and animals.

\section{Materials and methods}

\section{Collection of Anastetica hierochuntica (Kaff-e-Maryam)}

The whole plants were collected from different geographical regions of Saudi Arabia. The local name of this plant is "Kaff-e-Maryam". The plant was morphologically identified by Herbarium center at the Botany \& Microbiology department, King Saud University. The plant samples were sealed in sterilized polythene bags, were brought to the laboratory, and washed thoroughly 2-3 times with running tap water and once with sterile water, oven-dried for $1 \mathrm{~h}$ at $160^{\circ} \mathrm{C}$ and put in the shade in an aerated place till complete drying, then whole plant were ground using sterile coffee grinder into a fine powder.

\section{Preparation of plant extracts}

The prepared powder was soaked in each of ethanol and methanol solvents (plant material to solvent ratio was $1: 10, \mathrm{w} / \mathrm{v}$ ) and extracted for $24 \mathrm{hrs}$ at room temperature with shaking at $150 \mathrm{rpm}$. After filtration, solvents was evaporated under reduce pressure by using R-215 rotary evaporator (Sigma-Aldrich) until dryness. The solvent free brownish crude extract thus obtained was resuspended in dimethyl sulphoxide (DMSO) or phosphate buffered saline (PBS) to a final stock concentration of 50 $\mathrm{mg} / \mathrm{ml}$ or $100 \mathrm{mg} / \mathrm{ml}$. All extracts were stored at $4{ }^{\circ} \mathrm{C}$ in airtight dark bottles till use.

\section{Preparation of aqueous extract}

Powdered sample of $20 \mathrm{~g}$ was dissolved in $200 \mathrm{ml}$ of distilled water in conical flask the mouth of the conical flask was covered with aluminum foil and incubated in slow heat for $2 \mathrm{hrs}$. The residue was filtered by using muslin cloth followed by Whatman No. 1 filter paper, then centrifuged at $6000 \mathrm{rpm}$ for $10 \mathrm{~min}$. The supernatant was collected and further boiled till the volume was reduced to one-fourth of the original volume of the water used, and finally was evaporated by R-215 rotary evaporator (Sigma-Aldrich) and stored at $4{ }^{\circ} \mathrm{C}$.

\section{Pathogenic bacterial species}

Bacterial species used in this study (Table 1) were clinical isolates obtained from Botany and Microbiology Department, Faculty of Science, King Saud University. All of the bacterial species were grown and maintained on Muller Hinton agar or Trypticase Soy Agar media at $37^{\circ} \mathrm{C} \mathrm{pH}(7.3 \pm 0.2)$. All bacterial species were identified and characterized by culturing in the specific appropriate media followed by the rapid testing (Gram's stain, catalase, oxidase, coagulase, and bile solubility) and the biochemical testing (IMVIC) (Indole, methyl red, Voges-Proskauer, and citrate), triple sugar iron, oxidation/fermentation, urease, and nitrate reduction).

Table 1: Bacterial species, media and cultivation conditions.

\begin{tabular}{cll}
\hline No. & Bacterial species & $\begin{array}{l}\text { Media and cultivation } \\
\text { conditions }\end{array}$ \\
\hline 1 & Klebsiella pneumoniae & $\mathrm{TSA}+\mathrm{YE}$ or MHA, $37^{\circ} \mathrm{C}$ \\
2 & Proteus mirabilis & $\mathrm{TSA}+\mathrm{YE}$ or MHA, $37^{\circ} \mathrm{C}$ \\
3 & Enterococcus faecalis & $\mathrm{TSA}+\mathrm{YE}$ or MHA, $37^{\circ} \mathrm{C}$ \\
4 & Salmonella typhimurium & $\mathrm{TSA}+\mathrm{YE}$ or MHA, $37^{\circ} \mathrm{C}$ \\
5 & Salmonella typhi & $\mathrm{TSA}+\mathrm{YE}$ or MHA, $37^{\circ} \mathrm{C}$ \\
6 & Streptococcus pyogenes & $\mathrm{TSA}+\mathrm{YE}$ or MHA, $37^{\circ} \mathrm{C}$ \\
7 & Shigella sonnei & $\mathrm{TSA}+\mathrm{YE}$ or MHA, $37^{\circ} \mathrm{C}$ \\
8 & Streptococcus faecalis & $\mathrm{TSA}+\mathrm{YE}$ or MHA, $37^{\circ} \mathrm{C}$ \\
9 & Listeria monocytogenes & $\mathrm{TSA}+\mathrm{YE}$ or MHA, $37^{\circ} \mathrm{C}$ \\
10 & Bacillus subtilis & $\mathrm{TSA}+\mathrm{YE}$ or MHA, $37^{\circ} \mathrm{C}$ \\
\hline
\end{tabular}

TSA: Trypticase Soy Agar; YE: Yeast Extract; MHA: Mueller-Hinton Agar. 


\section{Bacterial species inoculums}

The tested bacterial species were first inoculated into tubes contains Mueller-Hinton Broth separately and incubated at $37^{\circ} \mathrm{C}$ for $18 \mathrm{hrs}$. Each of the cultures was then adjusted to $0.5 \mathrm{McFarland}$ turbidity standard at (1$\left.2 \times 10^{6} \mathrm{CFU} / \mathrm{mL}\right)$ and inoculated $(0.2 \mathrm{ml}$ each) onto Mueller Hinton agar plates (diameter: $15 \mathrm{~cm}$ ).

\section{In vitro cytotoxicity assay}

African green monkey kidney cells (Vero) were cultured in Dulbecco's modified eagle's medium (DMEM) supplemented with $10 \%$ fetal bovine serum (FBS; Gibco, Grand Island, NY), $2 \mathrm{mM}$ L-glutamine, penicillin (100 $\mathrm{U} / \mathrm{ml})$, streptomycin $(100 \mu \mathrm{g} / \mathrm{ml})$, and amphotericin B $(0.25 \mu \mathrm{g} / \mathrm{ml})$ (Sigma, St. Louis, MO). Cells treated with medicinal plant extracts were kept in maintenance medium containing $1 \%$ FBS, L-glutamine and antibiotics. Cells were incubated at $37^{\circ} \mathrm{C}$ with $5 \% \mathrm{CO}_{2}$ for 3 days.

\section{Microscopic examination for morphological alterations}

Monolayer cultures of Vero cells (80 to $90 \%$ confluence) were prepared in 96 well plates. After removal of culture medium, cells were washed twice with phosphate buffered saline. Two-fold serial dilutions of the methanol, ethanol and aqueous extracts were prepared in maintenance medium starting from the concentration of 2500 to $4 \mu \mathrm{g} / \mathrm{ml}$, and added to cells in triplicates. Wells that received methanol $70 \%$ were served as positive controls and those that received maintenance media only were served as negative controls. All cultures were kept at $37^{\circ} \mathrm{C}$ in $\mathrm{CO}_{2}$ incubator for $72 \mathrm{hrs}$ with daily observation for morphological changes under phase contrast inverted microscope equipped with a digital camera (Olympus IX51, Tokyo, Japan) at 20 and 40X magnification. Cellular alterations were recognized in the form of cell rounding, granulation, vacuolation, degeneration and lysis, as well as detachment of the monolayer. The minimal toxic concentration (MTC) was identified as the least concentration that induce toxic effect(s) on culture cells as detected microscopically after $72 \mathrm{hrs}$ of incubation.

\section{Cell viability assay}

The number of viable cells was determined colorimetric assay, in 96-well plates. In independent set of experiment, following the incubation of confluent monolayer cultures of cells with two-fold dilution series of plant extracts for $72 \mathrm{hrs}, 20 \mu \mathrm{l}$ of Cell Titer-Blue (CTB) reagent (Promega, Madison, WI) were added to each well. DMSO treated cells were used as a positive control. After $4 \mathrm{hrs}$ of incubation at $37^{\circ} \mathrm{C}$, the optical density (OD) was measured in all plate wells using ELx880 microplate reader (BioTek, Winooski, VT) with wavelength $570 \mathrm{~nm}$. The cell viability was measured in each well using the following formula:

$$
\text { Cell viability }=\frac{\mathrm{OD} \text { (assay well) }-\mathrm{OD} \text { (positive control) }}{\mathrm{OD} \text { (cell control) }-\mathrm{OD} \text { (positive control) }} \times 100
$$

The $50 \%$ cytotoxicity concentration $\left(\mathrm{CC}_{50}\right)$ was calculated as the concentration of the plant extract that induced reduction in cell viability to $50 \%$.

\section{Assessment of antibacterial activity}

Antibacterial activity of the ethanol, methanol and aqueous extracts were screened by agar-well diffusion method as described by Perez et al. (1990 and 1994), Lino and Deogracious (2006). Briefly, the bacterial suspension was swabbed uniformly to the Petri dishes containing 20-30 Mueller-Hinton Agar (MHA) and the inoculum was allowed to dry for 5-10 min. Nine wells of 6-8 $\mathrm{mm}$ in diameter were made in the surface of inoculated (MHA) using sterile cork borer for different concentrations of the extract and controls. The $50 \mu \mathrm{L}$ from each extracts $(1,5,10,50,100,200,250$ and 500 $\mathrm{mg} / \mathrm{mL}$ ) was added into each well on the MHA plate and allowed to stand on the bench for $1 \mathrm{hr}$ for proper diffusion and thereafter incubated at $37^{\circ} \mathrm{C}$ for $24 \mathrm{hrs}$. After $24 \mathrm{hrs}$, antibacterial activity was determined by measurement of diameter zones of inhibition (mm) (against the tested bacterial species) around each of the extracts. Reference antibiotics disc were placed on the agar surface as positive control. Sterilized distilled water was served as negative controls in separate wells. These studies were performed in triplicate.

\section{Determination of minimum inhibitory concentration (MIC) and minimal bacterial concentration (MBC)}

The minimum inhibitory concentration (MIC) of the aqueous, ethanol and methanol extracts was determined for the tested bacterial species in triplicates at varying concentrations by tube dilution method. A tube containing $1 \mathrm{ml}$ of Mueller-Hinton broth was inoculated with a loopful of the tested bacteria previously diluted to 0.5 McFarland turbidity standard. A tube containing Mueller-Hinton broth only was seeded with the tested bacteria to serve as control. All the tubes were then 
incubated at $37^{\circ} \mathrm{C}$ for $24 \mathrm{hrs}$ and then examined for growth by observing turbidity. The minimum bactericidal concentration (MBC) of the plant extract on the tested bacterial species was carried out according to (Ajaiyeoba et al., 2003; Dulger and Aki, 2009). Briefly, $1 \mathrm{ml}$ from the MIC tubes showing no growth was subcultured on to MHA plate and incubated at $37^{\circ} \mathrm{C}$ for 24 hrs. The MBC was defined as the lowest concentration of bacteria that showed no bacterial colony. All samples were examined in triplicate.

\section{Monitoring bacterial growth at various time points}

To study the bacterial growth at various time intervals, methanolic extract was diluted with nutrient broth to final concentrations of $0.3 \%$. Single colonies of the tested bacteria were used for inoculation of Luria-Bertani (LB) media containing the $0.3 \%$ methanolic extract, and were incubated at $37^{\circ} \mathrm{C}$ for $72 \mathrm{hrs}$. The antibacterial activities of the A. hierochuntica was evaluated by measuring the optical density of bacterial growth turbidity at $1,6,12,24,48$ and $72 \mathrm{hrs}$ at $590 \mathrm{~nm}$ according to (Baeshin et al., 2005).

\section{Statistical analysis}

Microsoft Excel (2007) data sheets and Graphpad Prism Version 6.0 were used to analyze the data. $\mathrm{CC}_{50}$ values, which is the concentration that kills $50 \%$ of the test cells, was determined by Regression Analysis. All data were presented as means \pm S.D.

\section{Results}

\section{Cytotoxicity of $A$. hierochuntica extracts}

The cytotoxic activity was evaluated in vitro according to it is effect on cell morphology (microscopic examination) and the metabolic reduction of CTB reagent (colorimetric assay) Vero cells. The cytotoxic effect of A. hierochuntica extracts was low cyototoxic $(>1000 \mu \mathrm{g} / \mathrm{ml})($ Table 2).

Table 2: In vitro microscopic cell-based cytotoxicity assay.

\begin{tabular}{lllllllllll}
\hline \multirow{2}{*}{ The plant } & \multicolumn{7}{c}{ Concentrations $(\mu \mathrm{g} / \mathrm{ml})$} & & & \\
& $\mathbf{1 0 0 0}$ & $\mathbf{5 0 0}$ & $\mathbf{2 5 0}$ & $\mathbf{1 2 5}$ & $\mathbf{6 4}$ & $\mathbf{3 2}$ & $\mathbf{1 6}$ & $\mathbf{8}$ & $\mathbf{4}$ & $\mathbf{0}$ \\
\hline Anastatica hierochuntica & + & - & - & - & - & - & - & - & - & - \\
\hline Note: + = Positive (morphological alterations, cytopathic effect (CPE) forming), - = Negative (No morphological alterations, no CPE).
\end{tabular}

The maximum concentration of methanol, ethanol and assay was $2500 \mu \mathrm{g} / \mathrm{ml}$, the result presented in Table 3 and water extracts from A. hierochuntica used in cell viability Fig. 2 which indicate MTC and $\mathrm{CC}_{50}$ on Vero cell lines.

Table 3: The limit in vitro activity of the cytotoxicity assay of three extracts from A. hierochuntica on Vero cells as indicated by MTC and $\mathrm{CC}_{50}$.

\begin{tabular}{llc}
\hline \multirow{2}{*}{ The extracts } & Vero cells line & CC $_{50}^{*}$ \\
\cline { 2 - 3 } & MTC & $>1000$ \\
\hline Methanol, ethanol and aqueous & 2500 & $>100$ \\
\hline *Concentration are expressed as $\mu \mathrm{g} / \mathrm{ml}$. MTC: Minimum toxic concentration. $\mathrm{CC}_{50}: 50 \%$ cytotoxic concentration.
\end{tabular}

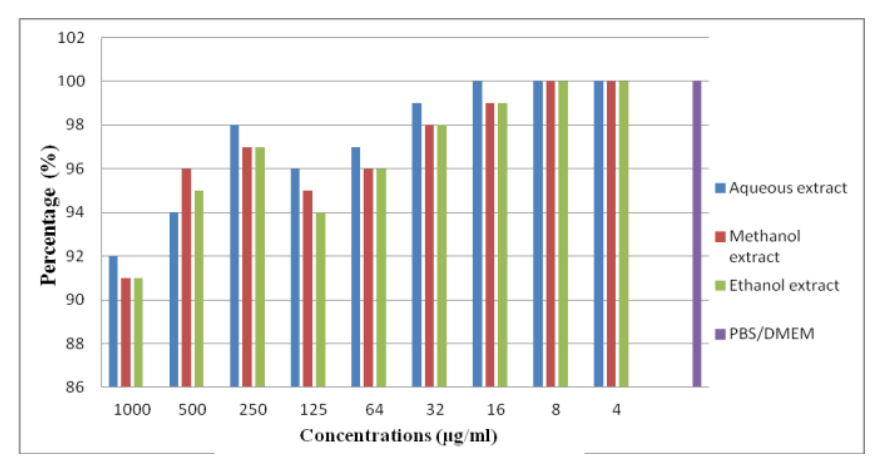

Fig. 2: In vitro cell viability as measured by CTB assay. Vero cells were incubated for $72 \mathrm{hrs}$ with the different concentration of three extracts. Cell viability was determined for each extract at various concentrations ranging from 1000 to $4 \mu \mathrm{g} / \mathrm{ml}$.

\section{Antibacterial activity}

The result of the antibacterial activity of the extracts obtained from A. hierochuntica against tested pathogenic bacteria that cause common and sometimes serious infections in human and animals are shown in (Table 1). The diameter of all inhibition zones were measured and compared (Table 4) and (Fig. 3). All the three extracts tested showed antibacterial activity with variable inhibition effects and different in their activities against pathogenic bacteria ranging from very strong inhibition $(22.7 \pm 1.3)$ to low $(4 \pm 0.6)$. Both methanolic and aqueous extracts of $A$. hierochuntica showed relatively similar antibacterial activity and inhibition effects against gram 
positive and negative bacteria (Klebsiella pneumoniae, Proteus mirabilis, Enterococcus faecalis, Salmonella typhimurium, Salmonella typhi, Streptococcus pyogenes, Shigella sonnei, Streptococcus faecalis, L. monocytogenes and Bacillus subtilis). Highest antibacterial activity was observed with methanol extract of A. hierochuntica against Klebsiella pneumoniae $(22.7 \pm 1.3)$ and $P$. mirabilis $(22.3 \pm 1.3)$ respectively, while moderate antibacterial activity was showed against Enterococcus

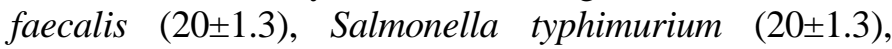

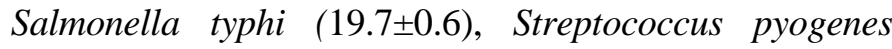
(19.7 \pm 0.6$)$, Shigella sonnei (19 mm), Streptococcus faecalis (20.8 \pm 1.3$)$ and Bacillus subtilis (21.6 \pm 1.6$)$ whereas minimum activity was observed against $L$. monocytogenes with inhibition zone $(4 \pm 0.6)$ (Table 4 and Fig. 3).

Table 4. The inhibitory effect of methanol, ethanol and water extracts of the A. hierochuntica at $100 \mathrm{mg} / \mathrm{ml}$ against investigated bacterial species.

\begin{tabular}{|c|c|c|c|c|c|}
\hline \multirow{2}{*}{ No. } & \multirow{2}{*}{ Tested bacterium } & \multicolumn{4}{|c|}{ Mean diameter zone of inhibition (mm) } \\
\hline & & $\mathbf{A Q}$ & ME & ET & DDW or PBS \\
\hline 1 & Klebsiella pneumoniae & $18 \pm 1.3$ & $22.7 \pm 1.3$ & $10.3 \pm 2.0$ & NI \\
\hline 2 & Proteus mirabilis & $20.3 \pm 1.3$ & $22.3 \pm 1.3$ & $13.3 \pm 0.6$ & NI \\
\hline 3 & Enterococcus faecalis & $17 \pm 0.9$ & $20 \pm 1.3$ & $11.0 \pm 0$ & $\mathrm{NI}$ \\
\hline 4 & Salmonella typhimurium & $18 \pm 0.6$ & $20 \pm 1.3$ & $10.7 \pm 2.0$ & NI \\
\hline 5 & Salmonella typhi & $18.7 \pm 0.9$ & $19.7 \pm 0.6$ & $11.0 \pm 0$ & NI \\
\hline 6 & Streptococcus pyogenes & $14 \pm 1.4$ & $19.7 \pm 0.6$ & $10 \pm 2.0$ & $\mathrm{NI}$ \\
\hline 7 & Shigella sonnei & $16 \pm 0.9$ & $19 \pm 0.9$ & $11.3 \pm 0.2$ & $\mathrm{NI}$ \\
\hline 8 & Streptococcus faecalis & $15.3 \pm 1.4$ & $20.8 \pm 1.3$ & $9.3 \pm 0.3$ & NI \\
\hline 9 & Listeria monocytogenes & NI & $4 \pm 0.6$ & NI & NI \\
\hline 10 & Bacillus subtilis & $18.7 \pm 0.9$ & $21.6 \pm 1.6$ & $10.3 \pm 2.0$ & $\mathrm{NI}$ \\
\hline
\end{tabular}

Antibacterial activities were expressed as mean inhibition diameter zones of the three replicates in millimeters (mm). Zone of inhibition not include the diameter of the well: NI: No Inhibition. (0 mm); AQ: aqueous extract; ME: methanol extract; ET: ethanol extract; DW: double distilled water; PBS: Phosphate-buffered saline. Values are expressed as mean of the three replicates.

The aqueous extract of $A$. hierochuntica showed highest antibacterial activity against Proteus mirabilis $(20.3 \pm 1.3$ $\mathrm{mm})$, Salmonella typhi $(18.7 \pm 0.9 \mathrm{~mm})$, Salmonella paratyphi $(18 \pm 0.6 \mathrm{~mm})$ and $K$. pneumoniae $(18 \pm 1.3 \mathrm{~mm})$ respectively, while it is showed comparatively similar antibacterial activity against Streptococcus faecalis, Streptococcus pyogenes, Shigella sonnei and Enterococcus faecalis, with no antibacterial activity against Listeria monocytogenes (Table 4 and Fig. 3). The methanol and ethanol extracts results showed over all similar antibacterial activity against tested organisms, except for Listeria monocytogenes. While, only a slight inhibition was observed with methanol extract (Table 4 and Fig. 3).

Fig. 3: Antibacterial activities profile (inhibitory zone in d鱼meter) of methanol, ethanol and water extracts of $A$.

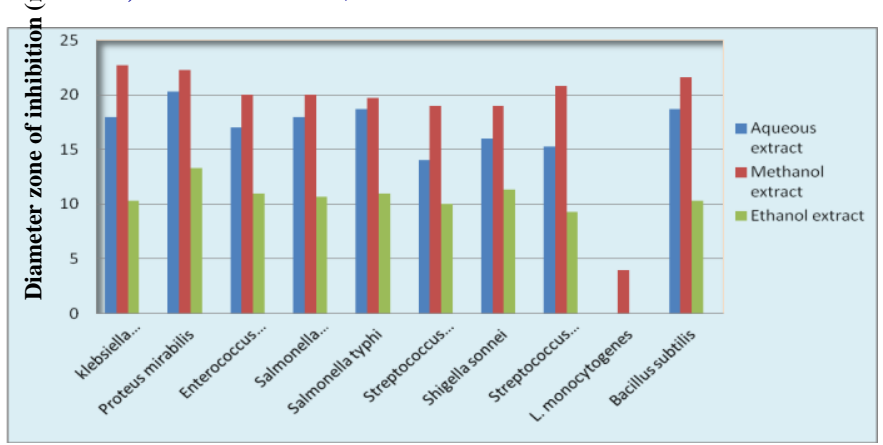

hierochuntica against tested bacterial species. Values are mean of three replicates.

\section{The minimum inhibitory concentration (MIC)}

The minimum inhibitory concentration (MIC) was determined for extracts which were found active in the antibacterial activity evaluation. The MIC ranged from $15-50 \mathrm{mg} / \mathrm{ml}$ (Fig. 4). Aqueous extract results showed 25, 30, 30, 40, 15, 15, 20, 25, 0 and $20 \mathrm{mg} / \mathrm{ml}$, MIC values for Klebsiella pneumoniae, Proteus mirabilis, Enterococcus faecalis, Streptococcus pyogenes, Salmonella typhi, Salmonella typhimurium, Shigella sonnei, Streptococcus faecalis, Listeria monocytogenes and Bacillus subtilis respectively (Fig. 4).

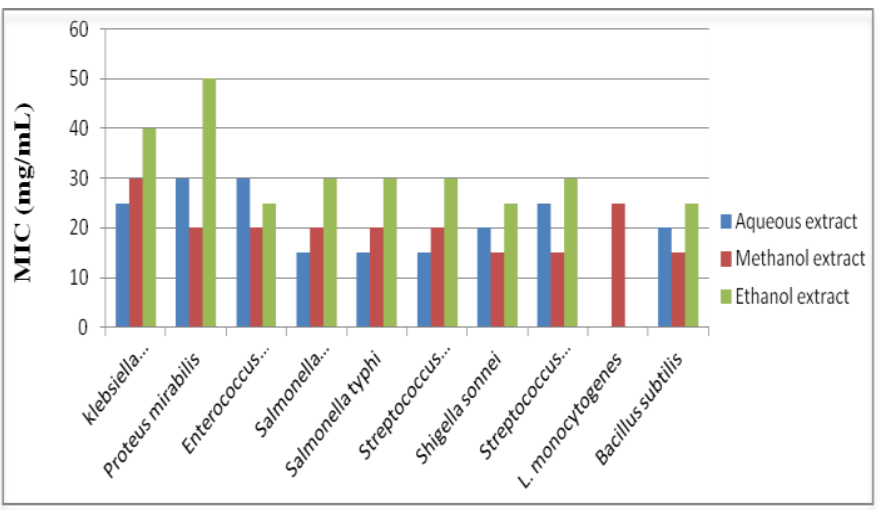

Fig. 4: Minimum Inhibitory Concentration (MIC) values of methanol, ethanol and water extracts. 
The MIC of methanol extract were 30, 20, 20, 20, 20, 20, $15,15,25,0$ and $15 \mathrm{mg} / \mathrm{ml}$ for Klebsiella pneumoniae, Proteis mirabilis, Enterococcus faecalis, Streptococcus pyogenes, Salmonella typhi, Salmonella typhimurium, Shigella sonnei, Streptococcus faecalis, Listeria monocytogenes and Bacillus subtilis respectively (Fig. 4), whereas the ethanol extract MIC values were 40, 50, 25, 50, 30, 30, 25, 30, 0 and $25 \mathrm{mg} / \mathrm{ml}$ against Klebsiella pneumoniae, Proteis mirabilis, Enterococcus faecalis, Streptococcus pyogenes, Salmonella typhi, Salmonella typhimurium, Shigella sonnei, Streptococcus faecalis, Listeria monocytogenes and Bacillus subtilis, respectively (Fig. 4).

\section{Bacterial growth at various time points}

Antibacterial activity of methanol extract from $A$. hierochuntica against the ten tested bacteria was further explored by incubating them in medium containing different concentrations of methanol extract of $A$. hierochuntica and monitoring the bacterial growth. Under the low concentration treatment $(0.3 \%)$ of methanol extract, the bacterial growth turbidity increased discontinuously during the whole period of treatment (72 hrs) (Fig. 5). However, under the higher concentrations treatment $(3 \%)$ of the methanol extract, the growth turbidity increased until $12 \mathrm{hrs}$ after the treatment and then considerably gradually decreased to the least at 72 hrs after the treatment (data on shown).

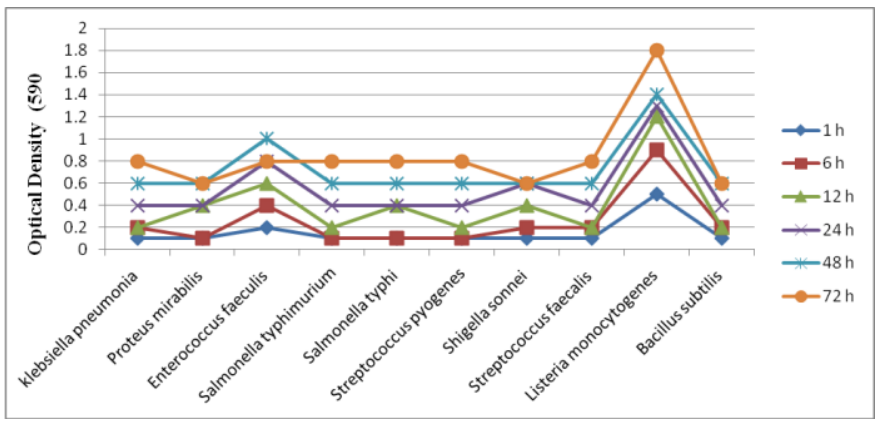

Fig. 5: Growth turbidity of methanol extract of $A$. hierochuntica against the tested bacteria treated with low concentration $(0.3 \%)$ of methanol extract.

\section{Discussion}

The major challenge facing the medical and public community is the shortage of antimicrobial compounds. This has arisen due to the overprescribing of unnecessary antibiotics and other antimicrobials; as a consequence of bacterial resistance, arising to antimicrobial compound (Sandle, 2014). Medicinal plants remain a major of potentially useful structures for the development of new chemotherapeutic agents (Fouchea et al., 2008). The first step towards this purpose is the in vitro cytotoxicity and antibacterial activity evaluation (Tona et al., 1998). Many studies have been screened antiviral, antibacterial, antifungal, anthelmintic, and anti-inflammatory properties of plants and whether they contain compounds with therapeutic activity or not (Samy et al., 2000; Palombo and Semple, 2001; Kumaraswamy et al., 2002; Bylka et al., 2004; Behera et al., 2005; Rosy et al., 2010). Some of these observations have helped in identifying the active principle responsible for such activities and in the developing drugs for the therapeutic use in human beings, antimicrobials of plant origin are effective in the treatment of several infections.

The plant used in this investigation was selected primarily on the basis of their folkloric medicinal properties and it is interesting that the exhibited antimicrobial activities correlated well with their traditional uses. Therefore, it is very essential to evaluate the cytotoxicity and antibacterial activity of $A$. hierochuntica. The bacterial species used in the present study were carefully selected because of their clinical importance, especially with the current increasing trends of multidrug resistance among emerging and re-emerging bacterial pathogens to the many available different antibiotics with their frequent uses. Recent scientific research has shown that many plants used in traditional medicine are potentially toxic, allergic, mutagenic, and/or carcinogenic (Ahmad et al., 1998; Dulger and Aki, 2009).

Therefore, in vitro cytotoxic evaluation studies are important to obtain effective safe new gents that have certain desirable properties such as: little or no toxic effects on normal cells, high efficacy on multiple sites, capability of oral consumption, known mechanism of action, low cost, and acceptance in the community (Aziz et al., 2003). Cytotoxicity testing of medicinal plants is not only important to evaluate and validate the safety of medicinal plants for traditional use, but also provides guidance in the search for new active compounds.

In the present study, the cytotoxic effect of the $A$. hierochuntica methanol, ethanol and water extracts were investigated in vitro on Vero cells using cell Titer-Blue (CTB) reagent. The cytotoxicity of $A$. hierochuntica extracts was evaluated on Vero cells in a dose dependent manner at the end of 72 hours incubation with the three extracts. The cytotoxicity indices low degrees of cellular degeneration at high concentration. In this regard, it is worthy to mention that the mean $\mathrm{CC}_{50}$ value of methanol, 
ethanol and water extracts in this study were lower than $1000 \mu \mathrm{g} / \mathrm{ml}$ (Tables 2, 3 and Fig. 3). In vitro cytotoxicity results indicated that the A. hierochuntica could not be belonging to the toxic plant. Therefore, the results obtained in this study supported that the A. hierochuntica may be considered as promising candidates for further evaluation against different kinds of other cell types both in vitro and in vivo.

In the current study, antibacterial activity of A. hierochuntica methanol, ethanol and water extracts have been evaluated in vitro against 10 pathogenic bacteria (Table 1), all three extracts tested showed antibacterial activity with variable inhibition effects and different in their activities against pathogenic bacteria ranging from very strong inhibition to low. However, the extracts differ in their activities against the microorganisms tested, increase of the extracts concentration from 50 to $100 \mathrm{mg}$ resulted in significant increase in the diameter zone of inhibition formed against all tested bacterium. Both methanolic and aqueous extracts of $A$. hierochuntica showed relatively similar antimicrobial activity and inhibition effects against gram positive and gram negative bacteria (Table 4 and Fig. 3). Highest antibacterial activity was observed with methanol extract of $A$. hierochuntica against Klebsiella pneumoniae and Protus mirabilis, while moderate antibacterial activity was showed against seven tested bacterium namely, Enterococcus faecalis, Salmonella typhimurium, Salmonella typhi, Streptococcus pyogenes, Shigella sonnei, Streptococcus faecalis and Bacillus subtilis, whereas minimum activity was observed against Listeria monocytogenes (Table 4 and Fig. 3). The aqueous extract of $A$. hierochuntica showed highest antibacterial activity against Proteus mirabilis, Salmonella typhi, Salmonella paratyphi and Klebsiella pneumoniae, while it showed comparatively similar antibacterial activity against Streptococcus faecalis, Streptococcus pyogenes, Streptoccos sonnei and Enterococcus faecalis, with no antibacterial activity against Listeria monocytogenes (Table 4 and Fig. 3). The methanol and ethanol extracts results showed over all similar antibacterial activity against tested organisms, except for Listeria monocytogenes, where only a slight inhibition was observed with methanol extract (Table 4 and Fig. 3). This suggests that some of the active compounds in the methanolic extract exist in higher percent than those in ethanolic and aqueous extracts. Correspondingly to the finding of the present study, many studies have been reported for A. hierochuntica methanol and aqueous extracts with Gram negative and positive bacteria (Mohamed et al., 2010). However, our finding differs from previous studies that noted alcohols to be reliable and consistent solvents for the extraction of antimicrobial substances from medicinal plants (Ahmad et al., 1998). This may be described by the fact that the secondary metabolites responsible for demonstrating antibacterial activity are greatly dependent on solvent system and collection process of metabolites from the plant sources (Rahman and Islam, 2013). Moreover, the geographical area and environment also affects the chemical composition of the plants and leads to the variation in activity (Girish and Satish 2008). Again, it was reported by several studies that several phytochemicals like terpenoids, flavonoids, tannins, alkaloids, steroids and some phenolic compounds are responsible for the antibacterial activity of the plant extract (Ramzi et al., 2008; Sule et al., 2011).

The mean zone of inhibition produced by the methanol, ethanol and water extracts from A. hierochuntica against tested bacterial species except Listeria monocytogenes were nearly similar to those produced by commercial standard antibiotic disc. This fact may be explained by the postulate that the crude form of plant extract might be contains high concentration of bioactive compounds. While screening medicinal plants for antibacterial activity, it is generally expected that a greater number of compounds would be active against Gram positive rather than Gram negative bacteria (Joshi et al., 2011). However, in the present study it was found that the extract of $A$. hierochuntica was effective against both gram positive and gram negative bacteria which suggest that the plant extract may possess broad spectrum of antibiotic compounds or simply general metabolic toxin (Mohamed et al., 2010). In a research conducted by Mohamed et al. (2010) using aqueous and methanolic extract of leaves of A. hierochuntica indicated that this plant showed better antibacterial activity effects against both Gram positive and Gram negative bacteria, except for L. monocytogenes. These results are quite similar to that of our present study although the sample preparation and some organisms were different. Antibacterial activity of Anastatica hierochuntica may involve complex mechanisms, like the inhibition of the synthesis of cell walls and cell membranes and proteins (Oyaizu et al., 2003). The extracts of A. hierochuntica contained flovonoids, Anastatin A, and B that were believed to be responsible for blocking protein synthesis in bacteria as well as have anti-carcinogenic, anti-inflammatory and antiparasitic effects and have possessed potential immune modulatory effects (Agarwal et al., 1998; Ma and Kinner, 2003; Antony et al., 2007). 
The results of present investigation clearly indicate that the antibacterial activity vary with the type of the solvent used. The results obtained in this study clearly revealed that $A$. hierochuntica possess potential antibacterial activity and inhibition effects against tested bacterium, albeit methanol extract was found to have shown the strong inhibition and broadest spectrum antibacterial activity against Gram positive and Gram negative bacteria.

The minimum inhibitory concentration (MIC) of methanol, ethanol and water extracts of the $A$. hierochuntica extracts against Gram positive and negative bacteria (Table 4 and Fig. 2) showed dissimilar minimum inhibitory concentration against different tested bacterial species, the solubility of phytochemicals in different solvents may led to the difference observed in the inhibitory activity results of the various extracts. There are many reports on solubility of different bioactive components in different solvents according to their polarity (Marjorie, 2001). However, the inhibitory activity of the extracts may be due to complex mechanisms such as interference with cell wall and membrane synthesis, synthesis of protein and nucleic acids (Oyaizu et al., 2003).

\section{Conflict of interest statement}

Author declares that he has no conflict of interest.

\section{Acknowledgement}

The author would like to thankful Dr. Maaweya Elaeed H. Awadalla, Botany \& Microbiology Department, King Saud University, and the Herbarium center, King Saud University, Riyadh, Saudi Arabia for their support in plant identification.

\section{References}

Agarwal, R., Kharya, M. D., Shrivastava, R., 1998. Antimicrobial and anthelmintic activities of the Anastatica hiero-cuntica. Ind. J. Exp. Biol. 29, 2292-2294.

Ahmad, I., Mehmood, Z., Mohammad, F., 1998. Screening of some Indian medicinal plants for their antimicrobial properties. J. Ethnopharmocol. 62, 183-193.

Ajaiyeoba, E. O., Onocha, P. A., Nwozo, S. O., Sama, W., 2003. Antimicrobial and cytotoxicity evaluation of Buchholzia coriacea stem bark. Fitoter. 74, 706-709.

Antony, P. J., Fyfe, L., Smith, H., 2007. Plant active components-a source for anti-parasitic agents. Trend. Parasitol. 21, 462-468.

Aziz, M. H., Kumar, R., Ahmad, N., 2003. Cancer chemoprevention by resveratrol: in vitro and in vivo studies and the underlying mechanisms. Int. J. Oncol. 23, 17-28.

Baeshin, N. A., Twaty, N., Al-Hebshi, A.,. 2005. Evaluation the genotoxicity of Rhazya stricta leaves extract by the Saccharomyces cerveisiae auxotrophic mutats test. Egyp. J. Nat. Toxicol. 2, 87-100.

Batanouny, K. H., 1999. Wild Medicinal Plants in Egypt. The Palm Press, Cairo. 207p.

Behera, S. K., Misra, M. K., 2005. Indigenous phytotherapy for genito-urinary diseases used by the Kandha tribe of Orissa, India. J. Ethnopharmacol. 102, 319-325.

Bellakhdar, J., Claisse, R., Fleurentin, J., Younos, C., 1991. Repertory of standard herbal drugs in the Moroccan pharmacopoea. J. Ethnopharmacol. 35, 123-143.

Bylka, W., Szaufer-Hajdrych, M., Matalawskan, I., Goslinka O., 2004. Antimicrobial activity of isocytisoside and extracts of Aquilegia vulgaris L. Lett. Appl. Microbiol. 39, 93-97.

Daur, I., 2012. Chemical properties of the medicinal herb Kaff Maryam (Anastatica hierochuntica L.) and its relation to folk medicine use. Afr. J. Microbiol. Res. 6, 5048-5051.

Doughari, J. H., El-mahmood, A. M., Manzara, S., 2007. Studies on the antibacterial activity of root extracts of Carica papaya L. Afr. J. Microbiol. Res. 037-041.

Dulger, G., Aki, C., 2009. Antimicrobial activity of the leaves of endemic Stachys pseudopinardii in Turkey. Trop. J. Pharm. Res. 8, 371-375.

El-Ghazali, G. E., Al-Khalifa, K. S., Saleem, G. A., Abdallah, E. M., 2010. Traditional medicinal plants indigenous to Al-Rass province, Saudi Arabia. J. Med. Plant Res. 4, 2680-2683.

Eman, A. S., Tailang, M., Benyounes, S., Gauthaman, K., 2011. Antimalarial and hepatoprotective effects of entire plants of Anastatic hierochuntica. Int. J. Res. Phytoch. Pharm. 1, 24-27.

Franklin, T. J., Snow, C. A., 1989. Biochemistry of antimicrobial action. $4^{\text {th }}$ Edn. Chapman and Hall, New York. pp.134-155.

Girish, H. V., Satish, S., 2008. Antibacterial activity of important medicinal plants on human pathogenic bacteria - a comparative analysis. World Appl. Sci. J. 5, 267-271.

Hegazy, A. K., Barakat, H. N., Kabiel, H. F., 2006. Anatomical significance of the hygrochastic movement in Anastatica hierochuntica. Ann. Bot. 97, 47-55.

Jaradat, N., 2005. Medical plants utilized in Palestinian folk medicine for treatment of diabetes mellitus and cardiac diseases. J. Al-Aqsa Univ. 9, 1-22.

Joshi, B., Sah, G. P., Basnet, B. B., Bhatt, M. R., Sharma, D., Subedi, K., Pandey, J., Malla, R., 20110. Phytochemical extraction and antimicrobial properties of different medicinal plants: Ocimum sanctum (Tulsi), Eugenia caryophyllata (Clove), Achyranthes bidentata (Datiwan) and Azadirachta indica (Neem). J. Microbiol. Antimicrob. $3,1-7$.

Junaid, S. A., Olabode, A. O., Onwuliri, F. C., Okworiu, A. E. J., Agina, S. E., 2006. The antimicrobial properties of 
Ocimum gratissimum extracts on some selected bacterial gastrointestinal isolates. Afr. J. Biotechnol. 5(22), 23152321.

Khalifa, T. I., Ahmad, M. A., 1980. Pharmacognostical study of certain species of Anastatica. PhD thesis, University of Cairo, Egypt.

Kubmarawa, D., Ajoku, G. A., Enwerem, N. M., Okorie, D. A., 2007. Preliminary phytochemical and antimicrobial screening of 50 medicinal plants from Nigeria. Afr. J. Biotechnol. 6(14), 90-96.

Kumaraswamy, Y., Cox, P. J., Jaspars, M., Nahar, L., Sarker, S. D., 2002. Screening seeds of Scottish plants for antibacterial activity. J. Ethnopharmacol. 83, 73-77.

Lino, A., Deogracios, O., 2006. The in-vitro antibacterial activity of Annona senegalensis, Securidacca longipendiculata and Steanotaenia araliacea- Ugandan medicinl plants. Afr. Health Sci. 6(1), 31-35.

Ma, Q., Kinner, K., 2003. Chemoprevention by phenolic antioxi-dants. J. Biol. Chem. 292, 2577-2583.

Marjorie, M. C., 2001. Plant products as antimicrobial agents. Clin. Microbiol. Rev. 12(4), 564-582.

Mohamed, A. A., Khalil, A. A., El-Beltagi, H. E. S., 2010. Antioxidant and antimicrobial properties of kaff maryam (Anastatica hierochuntica) and doum palm (Hyphaene thebaica) Grasas Y Aceites. 61(1), 67-75.

Oyaizu, M., Fujimoto, Y., Ogihara, H., Sekimoto, K., Naruse, A., Naruse, U., 2003. Antioxidative and antimicrobial activities extracts from several utility plants. Food Preserv. Sci. 29, 33-38.

Palombo, E. A., Semple, S. J., 2001. Antibacterial activity of traditional medicinal plants. J. Ethnopharmacol. 77, 151157.

Perez, C., Anesini, C., 1994. In vitro antibacterial activity of Argentine folk medicinal plants against Salmonella typhi. J. Ethnopharmacol. 44(1), 41-46.

Perez, C., Paul, M., Bazerque, P., 1990. Antibiotic assay by agar-well diffusion method. Acta Biol. Med. Exp. 15, 113-
115.

Prescott, L., Harley, J., Klein, D. A., 2002. Microbiology. $5^{\text {th }}$ Edn. McGraw- Hill, London. pp.820-950.

Rahman, M. A., Islam, M. S., 2013. Antioxidant, antibacterial and cytotoxic effects of the phytochemicals of whole Leucas aspera extract. Asian Pac. J. Trop. Biomed. 3, 273-279.

Ramzi, A. A. M., Salah, A. A. A., Hasson, S., Althawab, F. M. N., Alaghbari, S. A. Z., Lindequist, U., 2010. Antimicrobial, antioxidant and cytotoxic activities and phytochemical screening of some Yemeni medicinal plants. eCAM. 7, 323-330.

Rosy, B. A., Joseph, H., Rosalie, 2010. Phytochemical, pharmacognostical, antimicrobial activity of Indigofera spalathoids Vahl. (Fabaceae). Int. J. Biol. Technol. 1, 1215.

Samy, R. P., Ignacimuthu, S., 2000. Antibacterial activity of some folklore medicinal plants used by tribals in Western Ghats in India. J. Ethnopharmacol. 69, 63-71.

Sandle, T., 2014. Novel methods to address antimicrobial resistance. SOJ Microbiol. Infect. Dis. 2, 1-2.

Sehab, A. S., Adam, Z. M., 1983. Cytological effects of medicinal plants in Qatar III. Mitotic effect of water extract of Anastatica hierochuntica L. on Allium cepa. Cytologia. 48, 343-348.

Sharif, M. D. M., Banik, G. R., 2006 . Status and utilization of medicinal plants in Rangamati of Bangladesh. Res. J. Agric. Biol. Sci. 2(6), 268-273.

Sule, W. F., Okonko, I. O., Omo-Ogun, S., Nwanze, J. C., Ojezele, M. O., Ojezele, O. J., Alli, J. A., Soyemi, E. T., Olaonipekun, T. O., 2015. Phytochemical properties and in vitro antifungal activity of Senna alata Linn. crude stem bark extract. J. Med. Plants Res. 5, 176-183.

Tona, L., Kambu, K., Ngimbi, N., Cimanga, K., Vlietinck, A.J., 1998. Antiamoebic and phytochemical screenin of some Congolese medicinal plants. J. Ethnopharmacol. 61, 57-65.

\section{How to cite this article:}

$\mathrm{Al}$ Sobeai, S. M., 2016. In vitro cytotoxicity and antibacterial evaluation of aqueous, methanolic and ethanolic extracts of Anastatica hierochuntica against pathogenic bacteria. Int. J. Curr. Res. Biosci. Plant Biol. 3(6), 1422. doi: http://dx.doi.org/10.20546/ijcrbp.2016.306.002 